\title{
ANALISIS KELAYAKAN EKONOMI PADA PEMBANGUNAN PERKANTORAN TOWER POROS MARITIM SURABAYA
}

\author{
Eka Nurus Sakinah'), I Nyoman Dita Pahang Putra'), dan Anna Rumintang1) \\ 1) Teknik Sipil, Universitas Pembangunan Nasional "Veteran" Jawa Timur, Surabaya, \\ Jawa Timur \\ ekanuruss@gmail.com
}

\begin{abstract}
The increasing population and business development in Surabaya have made large companies need space for their employees. Assessing the characteristic of a development project must conduct a feasibility study. One of the feasibility studies conducted is to conduct an economic feasibility analysis. This analysis is carried out to ensure that the project is feasible from an economic aspect. The purpose of this study is to determine how much the benefits and costs are obtained and the extent of its economic feasibility. The project that will be examined in this final project is the Surabaya Maritime Tower Poros office. Then the feasibility of this office development project is based on the calculation of the Benefit-Cost Ratio (BCR), Net Present Value (NPV), Internal Rate of Return (IRR), and Return on Investment (ROI). The results of this economic feasibility analysis obtained a positive NPV value of IDR.32,995,643,307.00, IRR value of $12.08 \%$, ROI of $15.76 \%$ and $B C R$ 3.2. Then the return on investment is calculated using an annual cash flow with a variable amount of 2 years 10 months and 8 days.
\end{abstract}

Keywords: feasibility study, NPV, IRR, BCR, payback period

\begin{abstract}
ABSTRAK
Meningkatnya penduduk dan berkembangnnya bisnis di Surabaya menjadikan perusahaan besar membutuhkan ruang untuk karyawannya. Menilai suatu karakteristik dari sebuah pembangunan proyek harus melakukan studi kelayakan. Salah satu studi kelayakan yang dilakukan adalah dengan melakukan analisis kelayakan ekonomi. Analisis ini dilakukan untuk memastikan bahwa proyek tersebut layak dilakukan secara aspek ekonomi. Tujuan penelitian ini untuk mengetahui seberapa besar keuntungan dan biaya yang didapatkan dan sejauh mana kelayakan ekonominnya. Proyek yang akan diteliti pada penelitian ini adalah perkantoran Tower Poros Maritim Surabaya. Kemudian kelayakan pada proyek pembangunan perkantoran ini didasarkan pada perhitungan Benefit Cost Ratio (BCR), Net Present Value (NPV), Internal Rate of Return (IRR), dan Return on Investment (ROI). Hasil analisis kelayakan ekonomi ini didapatkan nilai NPV positif sebesar Rp.32,995,643,307.00, nilai IRR sebesar 12.08\%, ROI 15.76\% dan BCR sebesar 3.2. Kemudian pengembalian investasi dihitung dengan aliran kas tahunan dengan jumlah tidak tetap didapatkan nilai jangka waktu 2 tahun 10 bulan 8 hari.
\end{abstract}

Kata kunci: kelayakan ekonomi, NPV, IRR, BCR, payback period 


\section{PENDAHULUAN}

Kawasan metropolitan Surabaya merupakan kawasan kota terbesar kedua di Indonesia setelah Kota Jakarta, dan juga merupakan ibukota provinsi Jawa Timur (Emmanuel, 2015). Surabaya kota yang sudah mulai berkembang, di lihat dari sisi pertumbuhan dan peningkatan penduduk yang sangat pesat, maka dari itu kota ini harus di kembangkan pertumbuhannya agar bisa menunjang peningkatan ekonomi serta bisa mengurangi jumlah angka pengangguran di Kota Surabaya ini. Menurut (Wresniwira, 2017), Pertumbuhan ekonomi di kota Surabaya sangat pesat oleh karena itu kita harus meningkatkan dan mengembangkan pembangunan dalam bidang pembangunan infrastruktur, pembangunan industri, permukiman sehingga sarana pendidikan. Guna untuk menyeimbangkan kebutuhan penduduk yang semakin meningkat. Menurut (Putra, 2018), perkembangan pembangunan infrastruktur memiliki potensi untuk meningkatkan nilai pasar tanah disekitarnya. Kota yang letaknya strategis di wilayah Indonesia bagian Timur ini menjadi pusat perindustrian, perdagangan serta pusat untuk berbisnis.
Berkembangnya Industri di kota ini menjadikan Kota Surabaya dilirik oleh para pengusaha atau investor untuk menanamkan modalnya di kota ini. Menurut (Maulanasari et al., 2015), beberapa perusahaan besar sudah mulai mengembangkan bisnisnya sehinga membutuhkan ruang untuk karyawannya. Seperti contohnya perkantoran yang bisa disebut komersial real estate. Perkantoran ini memiliki banyak macam tipe bangunan sehingga bisa saja menjadikan suatu alternatif untuk meluaskan bisnis yang menjanjikan keuntungan bagi para investor. Keputusan dalam menganalisis investasi mempunyai peran penting terhadap perkembangan atau pertumbuhan suatu perusahaan. Rencana pembangunan Perkantoran Tower Poros Maririm Surabaya yang perlu dilakukan analisis Kelayakan Ekonomi. Menurut (Trimintarsih, 2016) analisis kelayakan memiliki beberapa metode diantaranya analisis keuntungan dan biaya (Benefit Cost Ratio), nilai sekarang (Net Present Value), laju pengembalian modal (Internal Rate of Return) dan Return on Investment (ROI). Dalam penelitian ini juga menganalisis Payback Period yang bertujuan untuk mengetahui jangka waktu pengembalian biaya awal. 


\section{KAJIAN PUSTAKA}

\subsection{Net Present Value (NPV)}

Menurut (Armaeni, N. K., Widanan, I. W., \& Sriastuti, 2017), metode net present value ini sering digunakan untuk penilaian usulan proyek, apabila NPV positif maka dana yang diinvestasikan tersebut dapat menghasilkan PV arus kas lebih tinggi dari PV investasi awal. Dan sebaliknya apabila NPV negatif maka dana yang diinvestasikan tersebut dapat menghasilkan PV arus kas lebih rendah dari PV investasi awal. Berikut adalah rumus net present value:

$$
\begin{aligned}
\mathrm{NPV}= & \sum_{\mathrm{i}=0}^{\mathrm{n}=0}\left[\left(\mathrm{~b}_{\mathrm{i}}-\mathrm{c}_{\mathrm{i}}\right)\left(1+\left(\frac{\mathrm{r}}{100}\right)\right)^{\mathrm{i}}\right]^{-1} \ldots \ldots \quad(1) \\
\text { dimana: } & \\
\mathrm{NPV}= & \text { nilai sekarang bersih } \\
\mathrm{b}_{\mathrm{i}}= & \text { manfaat pada tahun } \mathrm{i} \\
\mathrm{c}_{\mathrm{i}}= & \text { biaya pada tahun } \mathrm{i} \\
\mathrm{r} \quad= & \text { suku bunga diskonto } \\
& (\text { discount rate }) \\
\mathrm{n} \quad & \text { umur ekonomi proyek, } \\
& \text { dimulai dari tahap } \\
& \text { perencanaan sampai akhir. }
\end{aligned}
$$

Apabila NPV positif atau NPV $>0$ maka kriteria kelayakan ekonomi pada proyek diterima. Sebaliknya apabila NPV $<0$ maka kriteria usulan proyek tersebut tidak layak, apabila NPV $=0$ maka usulan proyek tersebut netral dan perlu ditinjau kembali (W, 2015).

\subsection{Internal Rate Return (IRR)}

Metode tingkat pengembalian internal (internal rate of return) berdasarkan pada nilai tingkat bunga (discount rate) dimana tingkat bunga yang menyamakan present value cash inflow dengan jumlah investasi awal dari proyek yang akan dinilai (Yasuha \& Saifi, 2017). Berikut rumus internal rate of return:

$$
\operatorname{IRR}=i_{1}+\left(i_{2}-i_{1}\right) \frac{\mathrm{NPV}_{1}}{\mathrm{NPV}_{1}+\mathrm{NPV}_{2}} \ldots \ldots .
$$

dimana:

$$
\begin{aligned}
\text { IRR = } & \text { arus pengembalian internal } \\
i_{1}= & \text { tingkat bunga yang } \\
& \text { menghasilkan NPV negatif } \\
& \text { terkecil } \\
i_{2}= & \text { tingkat bunga yang } \\
& \text { menghasilkan NPV positif } \\
& \text { terkecil } \\
\mathrm{NPV}_{1}= & \text { nilai sekarang dengan } \\
& \text { menggunakan i1 } \\
\mathrm{NPV}_{2}= & \text { nilai sekarang dengan } \\
& \text { menggunakan } \mathrm{i}_{2}
\end{aligned}
$$

Apabila IRR > discount factor, maka usulan proyek diterima. Sebaliknya, apabila IRR < discount factor, maka usulan proyek tersebut belum dapat diterima (Prastiwi \& Utomo, 2013).

\subsection{Return on Invesment (ROI)}

Metode ini digunakan untuk menilai keuangan suatu perusahaan yang berdasarkan pada arus kas bersih (A, 
2011). Berikut rumus return on investment:

$$
\mathrm{ROI}=\frac{\text { annual } \text { cash flow }}{\text { total cash } \text { invested }} \times 100 \% \ldots \ldots .
$$

\subsection{Benefit Cost Ratio (BCR)}

Menurut (Giatman, 2006), metode ini sebagai analisis tambahan dalam mengevaluasi yang telah diperhitungkan metode lain sebelumnya. Metode ini dilakukan dengan cara membandingkan manfaat dan biaya total yang telah dikonversikan ke dalam nilai uang sekarang (present value). Rumus untuk menghitung BCR sebagai berikut:

$$
\mathrm{BCR}=\frac{\text { present value benefit }}{\text { capital cost }} \times 100 \% \ldots
$$

Hasil BCR dari suatu proyek dikatakan layak secara ekonomi bila nilai BCR lebih besar dari 1 (BCR>1) (Amirullah et al., 2017).

\subsection{Payback Period (PP)}

Metode yang sering digunakan dalam mempertimbangkan tentang risiko untuk dapat mengetahui tingkat waktu dalam menutup kembali modal yang diinvestasikan. Menurut (Titin Amrih Wilujeng, Slamet Riyadi, 2019), payback period ialah jangka waktu yang diperlukan untuk mendapatkan kembali jumlah modal yang diinvestasikan, semakin cepat modal dapat diperoleh kembali berarti semakin kecil resiko yang dihadapi oleh perusahaan. Berikut rumus payback period:

$$
\text { Payback period }=\frac{\mathrm{n}+(\mathrm{a}+\mathrm{b}) \mathrm{x} 1}{(\mathrm{c}-\mathrm{b})} \ldots \ldots \ldots
$$

dimana:

$$
\begin{aligned}
\mathrm{n}= & \text { tahun terakhir dimana jumlah } \\
& \text { arus kas masih belum bisa } \\
& \text { menutup investasi mula-mula } \\
\mathrm{a}= & \text { jumlah investasi mula-mula } \\
\mathrm{b}= & \text { jumlah kumulatif arus kas pada } \\
& \text { tahun ke } \mathrm{n} \\
\mathrm{c}= & \text { jumlah kumulatif arus kas pada } \\
& \text { tahun } \mathrm{n}+1
\end{aligned}
$$

\section{METODE PENELITIAN}

Metode yang digunakan dalam menentukan analisis kelayakan ini berdasarkan dengan aspek biaya. Aspek biaya yang dimaksud seperti biaya pengembangan, pendapatan dan biaya operasional. Kemudian dari hasil penjabaran pembiayaan tersebut dianalisis kelayakan ekonominya. Perhitungan selanjutnya menggunakan kriteria investasi diantaranya, nilai sekarang (net present value), laju pengembalian modal (internal rate of return), keuntungan dan biaya (benefit cost ratio) dan juga menganalisis payback period untuk mengetahui jangka waktu pengembalian biaya awal. 


\section{HASIL DAN PEMBAHASAN}

\subsection{Analisis Biaya Pengembangan}

Biaya pengembangan ini didapatkan dari data sekunder yang diperoleh dari developer. Biaya pengembangan ini dikeluarkan bertahap sesuai aktivitas yang dilakukan. Pada tahun 2018, awal biaya pembangunan yang dikeluarkan untuk mengurus perizinan dan legal. Pada tahun yang sama biaya dikeluarkan untuk pekerjan persiapan dan pekerjaan struktur. Biaya pengembangan selanjutnya dikeluarkan pada tahun 2019, meliputi pekerjaan arsitektur, pekerjaan MEP, pekerjaan pembangunan masjid dan pekerjaan pembangunan power house. Kemudian pada tahun 2020 biaya yang dikeluarkan pekerjaan perkerasan jalan dan lansekap. Rekapitulasi biaya pengembangan dapat dilihat pada Tabel 1.

Tabel 1. Rekapitulasi Biaya Pengembangan

\begin{tabular}{cr}
\hline Tahun Ke- & Total Pengeluaran (Rp.) \\
\hline 0 & $159,245,311,840$ \\
1 & $265,950,702,000$ \\
2 & $7,249,921,000$ \\
Total & $432,445,934,000$ \\
\hline
\end{tabular}

\subsection{Analisis Biaya Operasional}

Biaya operasional merupakan biaya yang dikeluarkan oleh perusahaan. Biaya ini bertujuan untuk mendukung kelancaran operasional perusahaan dan juga salah satu faktor yang berpengaruh terhadap pencapaian pendapatan pada perusahaan. Dengan adanya pandemic Covid-19 ini, maka diasumsikan berhenti beroperasi dari Maret 2020 - Desember 2020. Kemudian kembali beroperasi pada awal tahun 2021 dengan asumsi kenaikan 10\%. Rekapitulasi biaya operasional dapat dilihat pada Tabel 2.

Tabel 2. Rekapitulasi Biaya Operasional

\begin{tabular}{cr}
\hline Tahun & \multicolumn{1}{c}{$\begin{array}{c}\text { Total Biaya } \\
\text { Operasional/Tahun }(\mathrm{Rp})\end{array}$} \\
\hline 2019 & $178,682,115$ \\
2020 & $197,757,286$ \\
2021 & $2,065,790,646$ \\
2022 & $337,866,498$ \\
2023 & $337,866,498$ \\
2024 & $337,866,498$ \\
2025 & $337,866,498$ \\
2026 & $337,866,498$ \\
2027 & $337,866,498$ \\
2028 & $337,866,498$ \\
2029 & $337,866,498$ \\
2030 & $337,866,498$ \\
2031 & $337,866,498$ \\
2032 & $337,866,498$ \\
2033 & $337,866,498$ \\
Total & $6,496,628,027$ \\
\hline
\end{tabular}

\subsection{Analisis Biaya Pendapatan}

Pendapatan proyek ini berasal dari sewa kantor per $\mathrm{m}^{2}$, sewa kantin per $\mathrm{m}^{2}$, dan tempat parkir. Pendapatan pada proyek ini dilakukan dengan mengasumsikan harga sewanya. Sewa perkantoran ini dilakukan secara bertahap. Pada tahun 
2019 dan 2020 sudah ada beberapa yang menyewa. Tetapi dengan adanya pandemi Covid-19 ini maka diasumsikan berhenti beroperasi dari maret 2020 - Desember 2020. Dan akan Kembali beroperasi pada awal tahun 2021 dengan asumsi kenaikan 10\%. Rekapitulasi pendapatan tahunan dapat dilihat pada Tabel 3.

Tabel 3. Rekapitulasi Biaya Pendapatan

\begin{tabular}{cr}
\hline Tahun & \multicolumn{1}{c}{ Total Biaya } \\
Pendapatan/Tahun (Rp.)
\end{tabular}

\subsection{Analisis Kelayakan}

\subsubsection{Analisis Net Operating Income}

Menurut (Khairinisa et al., 2020), salah satu metode penting dalam menganalisis kelayakan investasi. Setelah perusahaan mendapatkan pendapatan tahunan, selanjutnya bisa mencari nilai net operating income. Analisis net operating income dapat dilihat pada Tabel 4.

Tabel 4. Analisis Net Operating Income

\begin{tabular}{cr}
\hline Tahun & Net Operating Income $(\mathrm{Rp})$. \\
\hline 2018 & $(159,245,311)$ \\
2019 & $(263,535,932)$ \\
2020 & $(3,866,786)$ \\
2021 & $48,932,387$ \\
2022 & $61,210,878$ \\
2023 & $67,166,349$ \\
2024 & $74,107,419$ \\
2025 & $81,538,286$ \\
2026 & $89,712,239$ \\
2027 & $98,703,588$ \\
2028 & $108,594,071$ \\
2029 & $119,473,603$ \\
2030 & $131,441,088$ \\
2031 & $144,605,322$ \\
2032 & $159,085,978$ \\
2033 & $175,014,701$ \\
\hline
\end{tabular}

\subsubsection{Analisis Kelayakan Ekonomi}

Analisis kelayakan ekonomi dilakukan untuk mengetahui suatu pembangunan proyek yang layak dan menguntungkan bagi wilayah sekitarnya. Menurut (Torang Surya Siagian \& Sejahtera Surbakti, 2015), analisis ini memberikan perbedaan tentang manfaat dan biaya yang dikeluarkan, dimana manfaat (benefit) yang diperoleh semestinya lebih besar dibandingkan dengan biaya (cost) yang dikeluarkan. Hasil dari analisis ini didapatkan nilai NPV positif sebesar Rp.32,995,643,307, 
nilai IRR sebesar $13 \%$ dan BCR sebesar 3.2. Sehingga dapat disimpulkan pembangunan proyek perkantoran dianggap layak, karena memiliki nilai $\mathrm{NPV}<0$, IRR $<$ discount factor dan BCR $>1$.

\subsubsection{Analisis Return on Investment}

Analisis ini digunakan untuk menilai keuangan suatu perusahaan yang berdasarkan pada arus kas bersih. Berikut perhitungan ROI:

$$
\begin{aligned}
& \mathrm{ROI}=\frac{\text { annual cash flow }}{\text { total cash } \text { invested }} \times 100 \% \\
& \mathrm{ROI}=\frac{68,155,750,417}{432,445,934,000} \times 100 \%=15.76 \%
\end{aligned}
$$

\subsubsection{Analisis Payback Period}

Analisis payback period dilakukan dengan pendekatan pengeluaran dan pendapatan. Jangka waktu yang didapatkan dalam perhitungan payback period ini adalah 2 tahun 10 bulan 8 hari.

$$
\begin{aligned}
\text { Payback period } & =\frac{2(432.445+54.689) \times 1}{(155.900-54.689)} \\
& =2.855
\end{aligned}
$$

Untuk mencari secara detail pada bulan keberapa payback period tersebut didapatkan perhitungan sebagai berikut:

$$
\begin{aligned}
\text { Payback period } & =\mathrm{X} \times 12 \text { bulan } \\
& =0.855 \times 12 \\
& =10.26 \text { (10 bulan })
\end{aligned}
$$

\section{SIMPULAN DAN SARAN}

\subsection{Simpulan}

Hasil dari analisis kelayakan ekonomi didapatkan nilai NPV mencapai angka positif sebesar Rp.32,995,643,307, nilai IRR sebesar $12.08 \%$, nilai ROI sebesar $15.76 \%$ dan nilai BCR sebesar 3.2. Kemudian pengembalian investasi dihitung dengan aliran kas tahunan dengan jumlah tidak tetap didapatkan nilai jangka waktu 2 tahun 10 bulan 8 hari.

\subsection{Saran}

Dalam perhitungan biaya operasional harus lebih teliti agar estimasi dana lebih efisien dan tidak terbuang percuma.

\section{DAFTAR PUSTAKA}

A, L. S. M. (2011). Manajemen Keuangan Perusahaan (Baru). PT. RajaGrafindo Persada.

Amirullah, Saleh, S. M., \& Anggraini, R. (2017). Analisis Kelayakan Ekonomi Pembangunan Jalan Krueng Mane Buketrata Dengan Consumer Surplus. Jurnal Teknik Sipil, 1(2), 305-316.

Armaeni, N. K., Widanan, I. W., \& Sriastuti, D. A. N. (2017). Aalisis Risiko Pemodelan Cash Flow Proyek Investasi Real Estate di Kabupaten Badung dengan Program @Risk Paduraksa. Jurnal Teknik Sipil, 5(2), 46-62.

Emmanuel, D. P. (2015). Rezim Pertumbuhan Kota Surabaya Studi Tentang Pembangunan dan Revitalisasi Hotel di Surabaya. Jurnal Politik Muda, 4(1), 71-78. 
Giatman, M. (2006). Ekonomi Teknik (D. H. A. Aliludin (ed.); 1st ed.). PT. RAJAGRAFINDO PERSADA.

Khairinisa, R., Putra, I. N. D. P., \& Rumintang, A. (2020). Analisis Pembiayaan Investasi Pada Pembangunan Perumahan Taman Karangbahagia Tahap 1 Kabupaten Bekasi, Jawa Barat. PADURAKSA, 9, 1-10.

Maulanasari, A., Sipil, J. T., Teknik, F., Teknologi, I., Nopember, S., Arief, J., \& Hakim, R. (2015). Analisa Pembiayaan Investasi Properti Perkantoran di Jakarta Selatan. 4(2), 51-55.

Prastiwi, A., \& Utomo, C. (2013). Analisa Investasi Perumahan Green Semanggi Mangrove Surabaya. Jurnal Teknik Pomits, 2(2), 191-196.

Putra, I. N. D. P. (2018). Land Value Estimation Model as Impact of Infrastructure Development in Kaliwates Jember Indonesia. International Journal of Civil Engineering and Technology (IJCIET), 9(11), 1016-1030.

Titin Amrih Wilujeng, Slamet Riyadi, M. S. R. (2019). Analisis Swot Dan Aspek Keuangan Studi Kelayakan Investasi Pengembangan Rumah Sakit Umum Wonolangan Probolinggo. Ekonomi Dan Business, 4(2).

Torang Surya Siagian, R., \& Sejahtera Surbakti, M. (2015). Analisis Awal Kelayakan Eekonomi Dan Finansial Dalam Perencanaan Monorel Kota Medan. FSTPT Unila, September.

Trimintarsih, T. (2016). Analisis Kelayakan Investasi Di Usaha Jasa Transportasi Truk. Jurnal Revitalisasi, 5(4).

W, A. Y. (2015). Analisis Kelayakan Ekonomi Pembangunan Jalan
Tembus Lawang - Batu. Jurnal Teknik Sipil Untag Surabaya, 8(2), 235-252.

Wresniwira, M. I. H. (2017). Rezim Pertumbuhan Kota: Studi Pembangunan di Kecamatan Gunung anya. Jurnal Politik Muda, 6(2), 156-162.

Yasuha, J., \& Saifi, M. (2017). Analisis Kelayakan Investasi Atas Rencana Penambahan Aktiva Tetap (Studi kasus pada PT Pelabuhan Indonesia III (Persero) Cabang Tanjung Perak Terminal Nilam). Jurnal Administrasi Bisnis S1 Universitas Brawijaya, 46(1), 113-121. 